\title{
DESENVOLVIMENTO LARVAL DE DARDANUS INSIGNIS (SAUSSURE) (CRUSTACEA, DECAPODA, DIOGENIDAE), EM LABORATÓRIO
}

\author{
Nilton José Hebling 1 \\ Cynthia de Barros Mansur 1,2
}

\begin{abstract}
LARVAL. DEVElopMENT OF DARDANUS INSIGNIS (SALSSURE) (CRUSTACEA, DECAPOda, Diogenidak) REARED IN l.ABORATORY. The developmental stages of Dardanus insignis (Saussure, 1858) from first through eighth zoea and megalopa are described and illustrated. The experiments were carried out involving 100 larvae, obtained from ovigerous females collected on the north littoral of the state of São Paulo, Brazil. The larvae were kept in individual containers, with water of $34 \%$ salinity and fed with freshly hatched nauplii of Anemia: room temperature was maintained at $25+1^{\circ} \mathrm{C}$. The larval characters of this species are compared with Dardanus arrosor (Herbst, 1796), the only species of the genus that has also been reared in laboratory.

KEY WORDS. Crustacea, Diogenidae, Dardants insignis, larval development. hermit crab
\end{abstract}

Apesar de ser representado por cerca de 30 espécies (FOREST \& SAINT LAURENT 1967), o gênero Dardamus (Paulson, 1875) é muito pouco conhecido no que diz respeito ao desenvolvimento larval, sobretudo quanto à duração dos estágios e morfologia das zoeas mais adiantadas. Tais estudos tiveram início com o trabalho de ISSEL (1910) que, analisando amostras planctônicas coletadas no Mediterrâneo, identificou e descreveu o primeiro estágio de zoea de $D$. arrosor (Herbst, 1796), cujos resultados foram confirmados por BORASCHI (1921), Bourdillon-Casanova (1960) e Pike \& Williamson (1960). Posteriormente DECHANCÉ (1961), analisando material planctônico da costa ocidental da África, inferiu a existência de oito estágios de zoea no desenvolvimento larval de $D$. arrosor, D. callidus (Risso, 1827) e D. pectinatus (Ortmann, 1892), espécies que, presumivelmente, ocorriam na mencionada região. Esta mesma autora, logo a seguir, em 1962, estabeleceu algumas comparações morfológicas entre os dois primeiros estágios de zoea de $D$. arrosor e outras duas espécies não identificadas, oriundas da região Indopacífica. Além destas, foram publicadas as descrições morfológicas das megalopas de D. venosus (H. Milne-Edwards, 1848) D. scutellatus (H. Milne-Edwards, 1848) e D. insignis (Saussure, 1858), por Provenzano JR. (1963a, 1963b), o desenvolvimento larval completo de $D$.

1) Departamento de Zoologia, Instituto de Biociêneias, Universidade Estadual Paulista. Campus de Rio Claro. Caixa Postal 199. 13506-900 Rio Claro. Brasil.

2) Bolsista de Iniciação Científica da FAPESP. 
arrosor, por KURATA (1968) e a descrição do primeiro estágio de zoea de D. setifer (H. Milne-Edwards, 1836) por NAYAK \& KAKATI (1977).

Visando um melhor conhecimento e identificação das formas larvais dos crustáceos da ordem Decapoda, que ocorrem no litoral brasileiro, o presente trabalho tem por objetivo principal o estudo do desenvolvimento larval de Dardanus insignis, em laboratório, com a apresentação das figuras e descrições morfológicas que caracterizam cada um dos estágios, os intervalos de tempo entre as ecdises sucessivas e um estudo comparativo com as outras espécies do mesmo gênero, particularmente com $D$. arrosor.

\section{MATERIAL E MÉTODOS}

As fêmeas ovígeras de Dardanus insignis foram coletadas com o auxílio de uma rede do tipo "otter trawl", entre 14 e 18 metros de profundidade, no litoral norte do estado de São Paulo (2332’05" a $\left.23^{\circ} 33^{\prime} 20^{\prime \prime} \mathrm{S}, 45^{\circ} 05^{\prime} 30^{\prime \prime} \mathrm{W}\right)$.

Após o transporte para o laboratório, as fêmeas ovígeras foram mantidas isoladas, em aquários com 10 litros de água do mar de salinidade 34\%o, fotoperíodo natural e temperatura de $25 \pm 1^{\circ} \mathrm{C}$, até a eclosão das larvas (zoeas I).

Imediatamente após a eclosão, as zoeas foram atraídas por um foco de luz, removidas do aquário com o auxílio de um conta-gotas e individualizadas em 100 placas de Petri de $20 \mathrm{ml}$, providas de água do mar previamente filtrada e aerada, sob as mesmas condições de temperatura e salinidade em que eclodiram.

As larvas foram diariamente observadas para constatação da mortalidade e verificação da ocorrência de ecdises, com a conseqüente determinação das mudanças de estágio. A seguir, procedeu-se a troca de água das placas e introdução do alimento, que consistiu de cerca de 30 náuplius recém-eclodidos de Artemia sp., até o término do desenvolvimento larval.

As descrições morfológicas, as medidas e os desenhos foram efetuados com o auxílio de um microscópio óptico comum, provido de câmara clara e ocular micrométrica, a partir de larvas e exúvias fixadas e conservadas em uma mistura de álcool a $95 \%$ e glicerina, na proporção 1:1. Para cada estágio de desenvolvimento foram analisados cerca de dez indivíduos. Para o estágio de megalopa foram analisados também alguns exemplares obtidos no conteúdo estomacal de peixes, coletados na natureza.

O cultivo das larvas foi realizado, em linhas gerais, de acordo com as metodologias indicadas por Hebling \& FRANSOZO ( 1982) e RIEGER \& HEBLING (1993). A terminologia adotada baseou-se nos trabalhos de BROSSI-GARCIA \& HEbling (1983) e Negreiros-Fransozo \& HEBling (1983).

\section{RESULTADOS}

Pela análise das coletas mensais constatou-se que, na região estudada, as fêmeas ovígeras de $D$. insignis só foram encontradas após o início da primavera, entre os meses de outubro e dezembro.

Os resultados do cultivo das larvas, em laboratório, indicaram que o 
desenvolvimento larval de $D$. insignis é constituído por oito estágios de zoea e um de megalopa. Das 100 larvas individualizadas apenas 38 atingiram o oitavo estágio de zoea. Destas, somente três sofreram ecdise para megalopa, 17 morreram e 18 passaram por nova muda, continuando como zoeas. Tais zoeas remanescentes sofreram mais uma ou duas ecdises, sem alterações morfológicas que pudessem caracterizar um estágio adicional e morreram, sem atingir a megalopa.

A duração média acumulada de cada estágio, em dias, foi: zoea $\mathrm{I}=5,9$; zoea II $=9,9$; zoea $I I I=13,2$; zoea IV $=17$; zoea $V=20,2$; zoea $V I=23$, 8; zoea $\mathrm{VII}=27,9$; zoea $V I I I=37$. A duração da megalopa não foi obtida pelo fato dos três exemplares terem morrido, sem passar para o primeiro estágio juvenil.

\section{Descrição dos estágios larvais}

\section{ZOEA I (Figs 1-I a 10-I)}

Carapaça (Fig. 1-I) sem espinhos. O ápice da antena atinge o terço terminal do espinho rostral. Os olhos são sésseis. Abdome (Fig. 2-I) com cinco somitos, pois o último (sexto) é fundido ao telso. O quinto somito apresenta um par de espinhos póstero-laterais. O telso (Fig. 2-I) é subtriangular e apresenta duas estrias longitudinais paralelas. Na sua margem distal é provido de um entalhe mediano que o divide em duas partes simétricas providas, cada uma, de sete processos terminais, que lhe conferem a fórmula $7+7$. O primeiro processo é um pequeno espinho póstero-lateral, o segundo é uma pequena cerda simples e os demais são longas cerdas plumosas.

Antênula (Fig. 3-I). Unirreme, não segmentada. Em sua extremidade inserem-se quatro estetos e duas cerdas plumosas, sendo uma bem mais desenvolvida, subdistal.

Antena (Fig. 4-I). Exopodito com 10 (11) cerdas plumosas e minúsculas cerdas simples na margem externa; endopodito com duas cerdas plumosas e uma pequena cerda simples; protopodito com um espinho.

Mandíbula (Fig. 5-I). Processo incisivo com dois ou três dentes e processo molar com cinco ou seis.

Maxílula (Fig. 6-I). Endopodito constituído por um segmento, com duas longas cerdas simples distais e uma pequena cerda simples basal. Endito basal com três projeções espiniformes e duas pequenas cerdas simples subdistais. Endito coxal com seis cerdas plumosas distais.

Maxila (Fig. 7-I). Exopodito (escafognatito) com cinco cerdas plumosas marginais. Endopodito com duas cerdas simples distais, duas subdistais e minúsculas cerdas simples na margem externa. Endito basal com duas cerdas plumosas e uma simples no lobo distal e uma cerda plumosa e quatro simples no lobo proximal. Endito coxal com três cerdas plumosas e uma simples no lobo distal e uma cerda plumosa e quatro simples no lobo proximal, além de minúsculas cerdas simples na margem interna.

Primeiro maxilípede (Fig. 8-I). Protopodito com sete pequenas cerdas simples e um processo em forma de gancho, no ângulo látero-proximal, com duas 

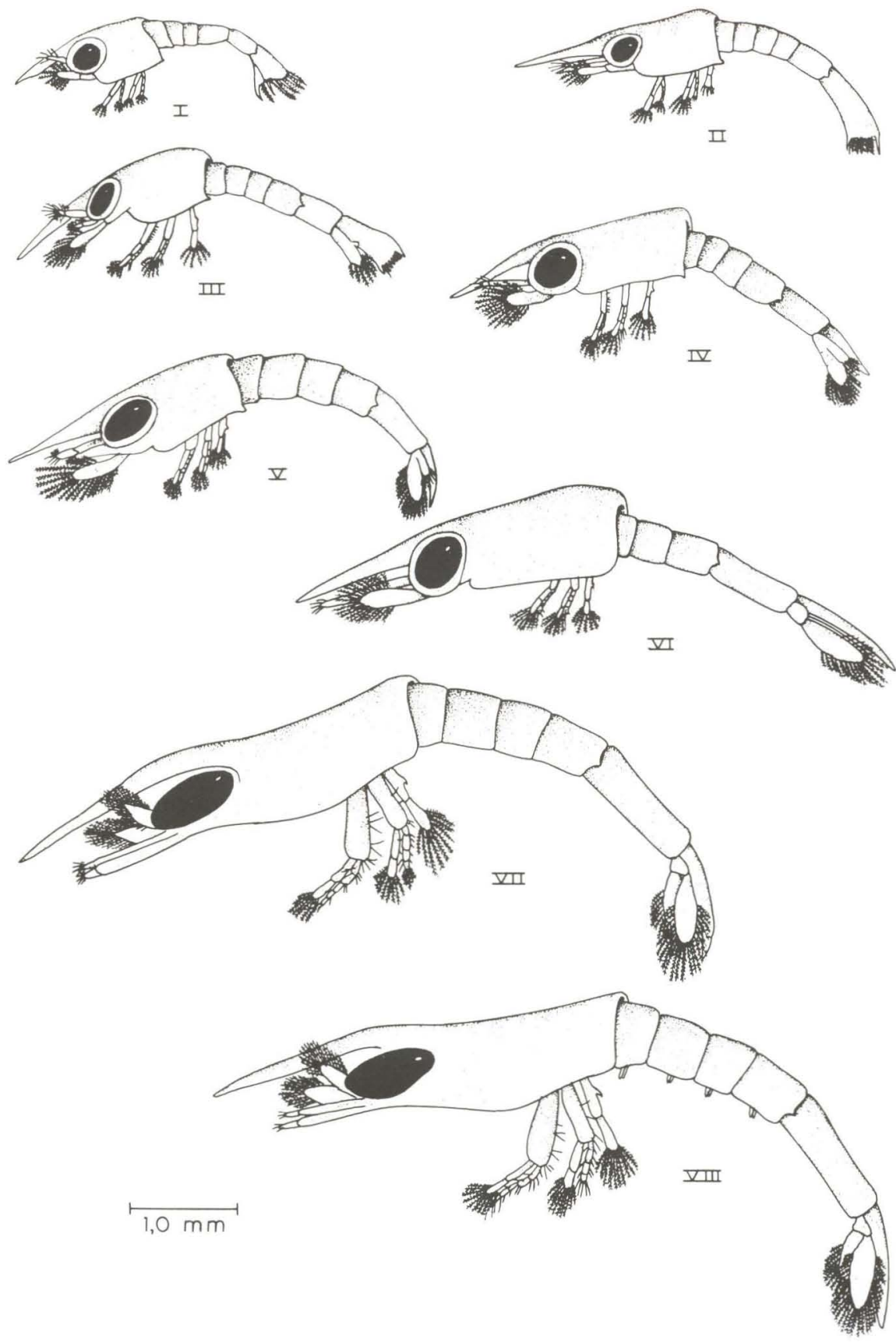

Fig. 1. Dardanus insignis. (I-VIII) Vista lateral dos estágios de zoea.

Revta bras. Zool. 12 (3): 471 - 491, 1995 
cerdas simples; endopodito 5-segmentado com 2-2-1-2-5 cerdas, do segmento proximal para o distal; exopodito imperfeitamente segmentado, com quatro cerdas natatórias.

Segundo maxilípede (Fig. 9-I). Protopodito com três pequenas cerdas; endopodito 4-segmentado com 2-2-2-5 cerdas, do segmento proximal para o distal; exopodito imperfeitamente segmentado com quatro cerdas natatórias.

Terceiro maxilípede (Fig. 10-I). Limitado a um bulho alongado, liso e imperfeitamente segmentado.

\section{ZOEA II (Figs 1-II a 10-II)}

Carapaça (Fig. 1-II) um pouco mais alongada que na zoea I. Rostro longo, com o ápice das antenas atingindo seu terço terminal. Olhos ligeiramente pedunculados. Abdome com cinco somitos e um par de espinhos póstero-laterais no quinto. O telso (Fig. 2-II ) ainda é subtriangular e apresenta as duas estrias longitudinais. $O$ entalhe mediano é bem menos acentuado que na zoea I e apresenta um par de cerdas, que conferem ao telso a fórmula $8+8$.

Antênula (Fig. 3-II). Unirreme, não-segmentada, com cinco estetos e uma cerda plumosa na região distal e três cerdas plumosas subdistais.

Antena (Fig. 4-II). Exopodito com 11 (12) longas cerdas plumosas e minúsculas cerdas simples na margem externa; endopodito com duas cerdas plumosas e uma pequena cerda simples; protopodito com um espinho.

Mandíbula (Fig. 5-II). Processo incisivo com três ou quatro dentes e molar com cinco ou seis dentes.

Maxílula (Fig. 6-II). Endopodito semelhante ao da zoea I; endito basal com quatro projeções espiniformes e duas pequenas cerdas simples; endito coxal com seis cerdas plumosas distais e uma peyuena cerda simples subdistal.

Maxila (Fig. 7-II). Exopodito com oito cerdas plumosas marginais; endopodito com duas cerdas simples terminais e duas subdistais; endito basal com quatro cerdas simples no lobo distal e cinco no lobo proximal; endito coxal com quatro cerdas simples no lobo distal e cinco no lobo proximal, sendo três delas com pouquíssimas plúmulas.

Primeiro maxilípede (Fig. 8-II). Protopodito com sete cerdas simples; endopodito com 3-3-2-2-5 cerdas, do segmento proximal para o distal, sendo algumas plumosas, outras não. Exopodito com seis cerdas natatórias.

Segundo maxilípede (Fig. 9-II). Protopodito com três cerdas simples; endopodito com 2-3-3-5 cerdas do segmento proximal para o distal, sendo algumas plumosas, outras não. Exopodito com seis cerdas natatórias.

Terceiro maxilípede (Fig. 10-II). Protopodito com hulbo de endopodito; exopodito imperfeitamente segmentado, com cinco cerdas natatórias.

\section{ZOEA III (Figs 1-III a 10-III)}

Carapaça (Fig. 1-III) com rostro semelhante ao da zoea II. Olhos pedunculados. O abdome apresenta o sexto somito individualizado, separado do telso, e com um par de espinhos póstero-laterais no quinto somito. O telso (Fig. 2-III) apresenta um par a mais de cerdas plumosas na região mediana; sua fórmula passa 


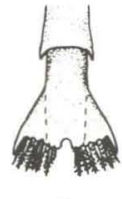

I
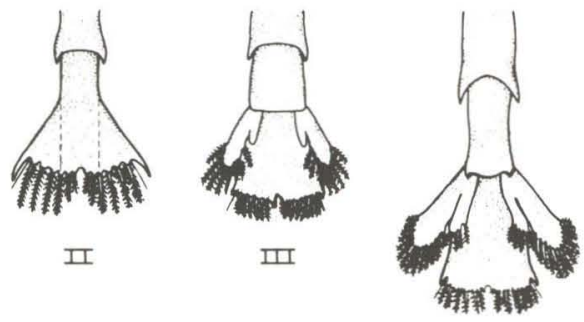

. IV

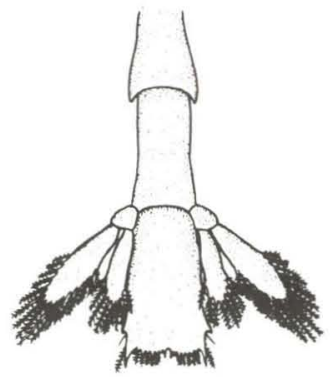

Z

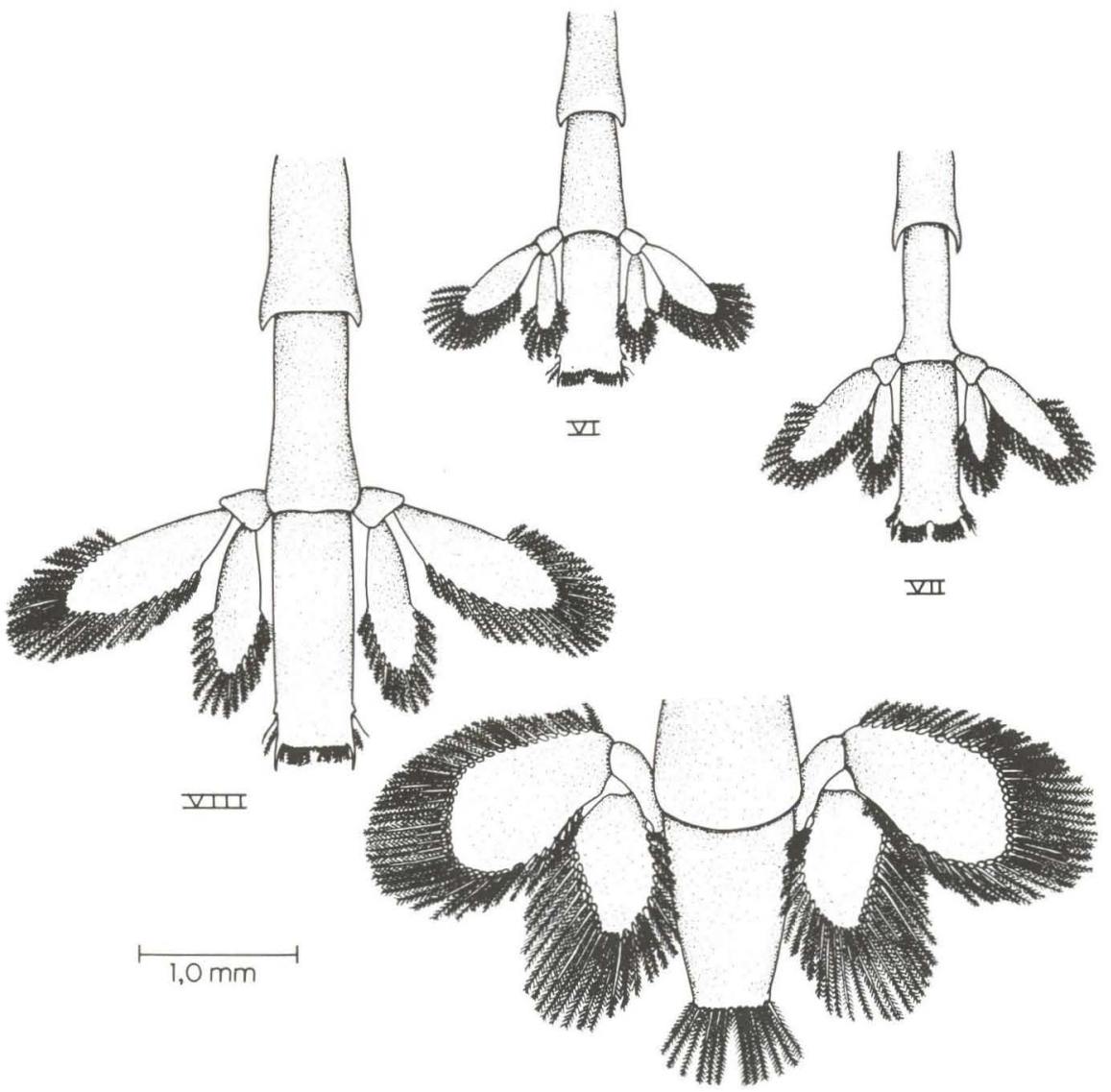

M

Fig. 2. Dardanus insignis. (I-VIII) Vista dorsal do telso e urópodo dos estágios de zoea; (M) megalopa. 


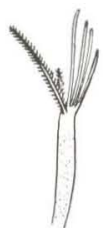

工

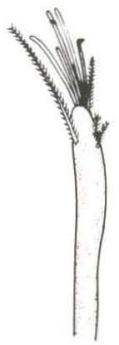

프

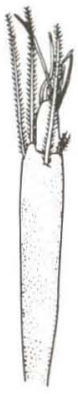

표

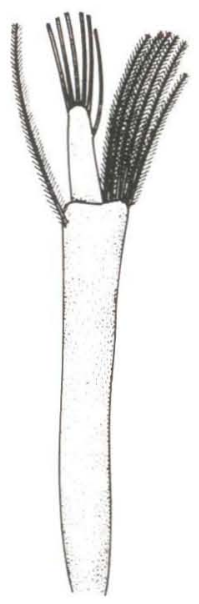

ZI

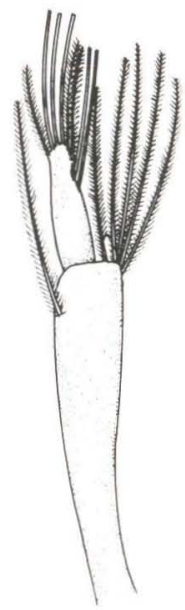

УII
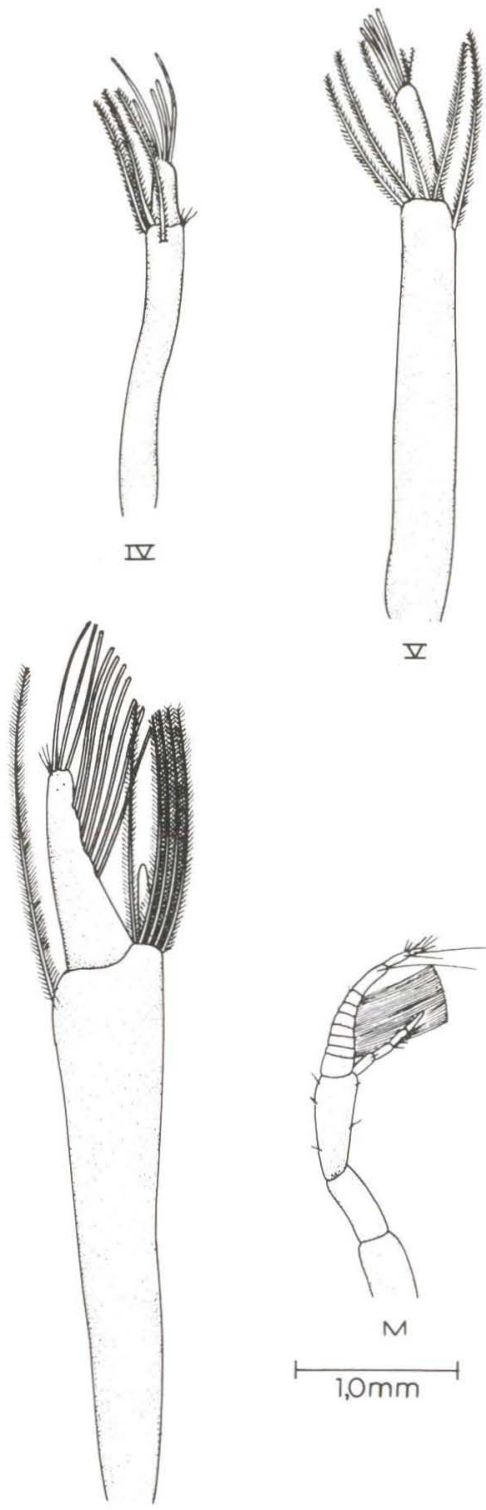

$\nabla$
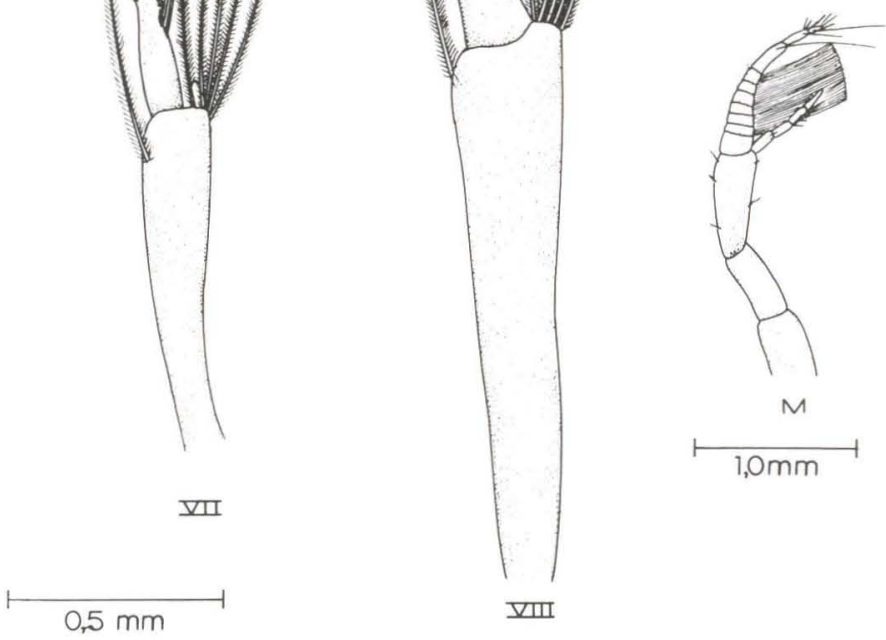

VIII

Fig. 3. Dardanus insignis. (I-VIII) Antênula dos estágios de zoea; megalopa (M).

a ser $9+9$. Surgem os urópodos, com exopodito provido de oito (7-10) cerdas plumosas, ausência de protopodito e apenas um bulbo de endopodito.

Antênula (Fig. 3-III). Unirreme, 2-segmentada, com cinco estetos no segmento distal (exopodito) e cinco cerdas plumosas no segmento proximal (basipodito). 
Antena (Fig. 4-III). Exopodito com 12 a 14 longas cerdas plumosas e minúsculas cerdas simples na margem externa; endopodito com uma única cerda simples na porção terminal. Protopodito com um espinho.

Mandihula (Fig. 5-III). Processo incisivo com três a cinco dentes. Processo molar em dois níveis, providos de um número variável de dentes, até mesmo entre os apêndices direito e esquerdo de um mesmo indivíduo.

Maxílula (Fig. 6-III). Endopodito não modificado. Endito basal com quatro projeções espiniformes e duas pequenas cerdas simples. Endito coxal com sete cerdas plumosas.

Maxila (Fig. 7-III). Exopodito com nove cerdas plumosas; endopodito não modificado. Endito basal com quatro cerdas simples no lobo distal e cinco no proximal. Endito coxal com quatro cerdas simples no lobo distal e seis no proximal.

Primeiro maxilípede (Fig. 8-III). Protopodito com oito cerdas simples; endopodito com 3-3-2-2-5 cerdas, do segmento proximal para o distal. Exopodito com seis cerdas natatórias.

Segundo maxilípede (Fig. 9-III). Protopodito com três cerdas (uma simples e duas plumosas); endopodito com 2-3-3-5 cerdas plumosas, do segmento proximal para o distal. Exopodito com seis cerdas natatórias.

Terceiro maxilípede (Fig. 10-III). Protopodito com bulbo de endopodito; exopodito com seis cerdas natatórias.

\section{ZOEA IV (Figs 1-IV a 10-IV)}

Carapaça (Fig. 1-IV) bastante semelhante a da zoea III. Telso (Fig. 2-IV) mais alongado que no estágio anterior, com $9+9$ processos. U rópodo desprovido de protopodito, com 14 (12-15) cerdas plumosas no exopodito e endopodito bem desenvolvido, com cinco ou seis cerdas plumosas.

Antênula (Fig. 3-IV). Unirreme, 2-segmentada, com cinco estetos na porção terminal do exopodito e três cerdas plumosas e três pequenas cerdas simples no protopodito.

Antena (Fig. 4-IV). Exopodito com 16 (15 a 17) longas cerdas plumosas; endopodito com uma única cerda simples na porção terminal. Protopodito com um espinho.

Mandíbula (Fig. 5-IV). Semelhante a da zoea III.

Maxílula (Fig. 6-IV). Endopodito não modificado. Endito basal com quatro projeções espiniformes e duas pequenas cerdas simples. Endito coxal com sete cerdas plumosas.

Maxila (Fig. 7-IV). Exopodito com 10 cerdas plumosas; endopodito não modificado; endito basal com quatro cerdas no lobo distal e cinco no proximal; endito coxal com quatro cerdas no lobo distal e seis no proximal.

Primeiro maxilípede (Fig. 8-IV). Protopodito com oito cerdas simples; endopodito com 4-3-2-2-5 cerdas plumosas, do segmento proximal para o distal. Exopodito com seis cerdas natatórias.

Segundo maxilípede (Fig. 9-IV). Protopodito com três cerdas (uma simples e duas plumosas); endopodito com 2-3-3-5 cerdas plumosas, do segmento proximal 

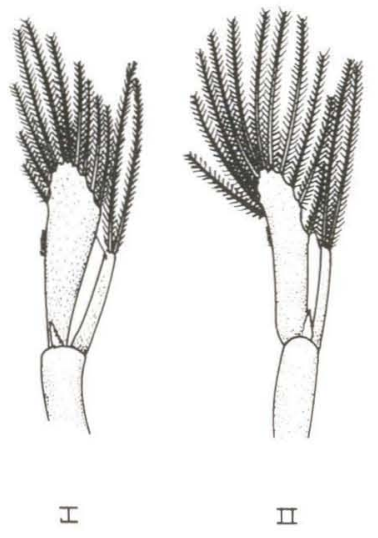

$0,5 \mathrm{~mm}$

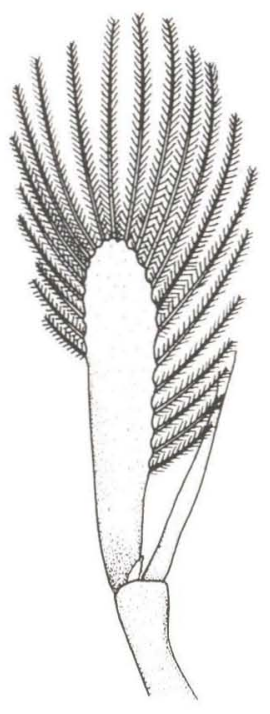

ZI
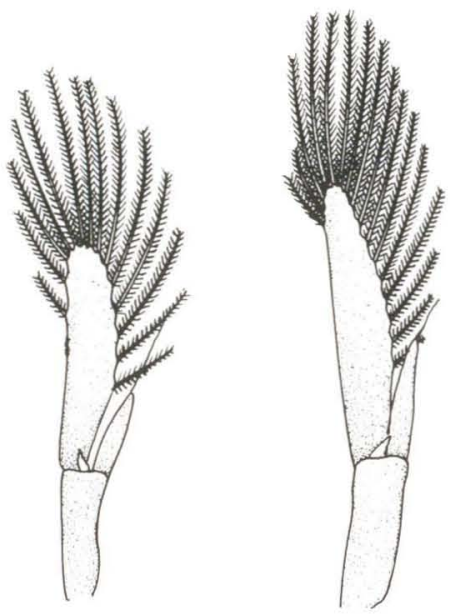

III
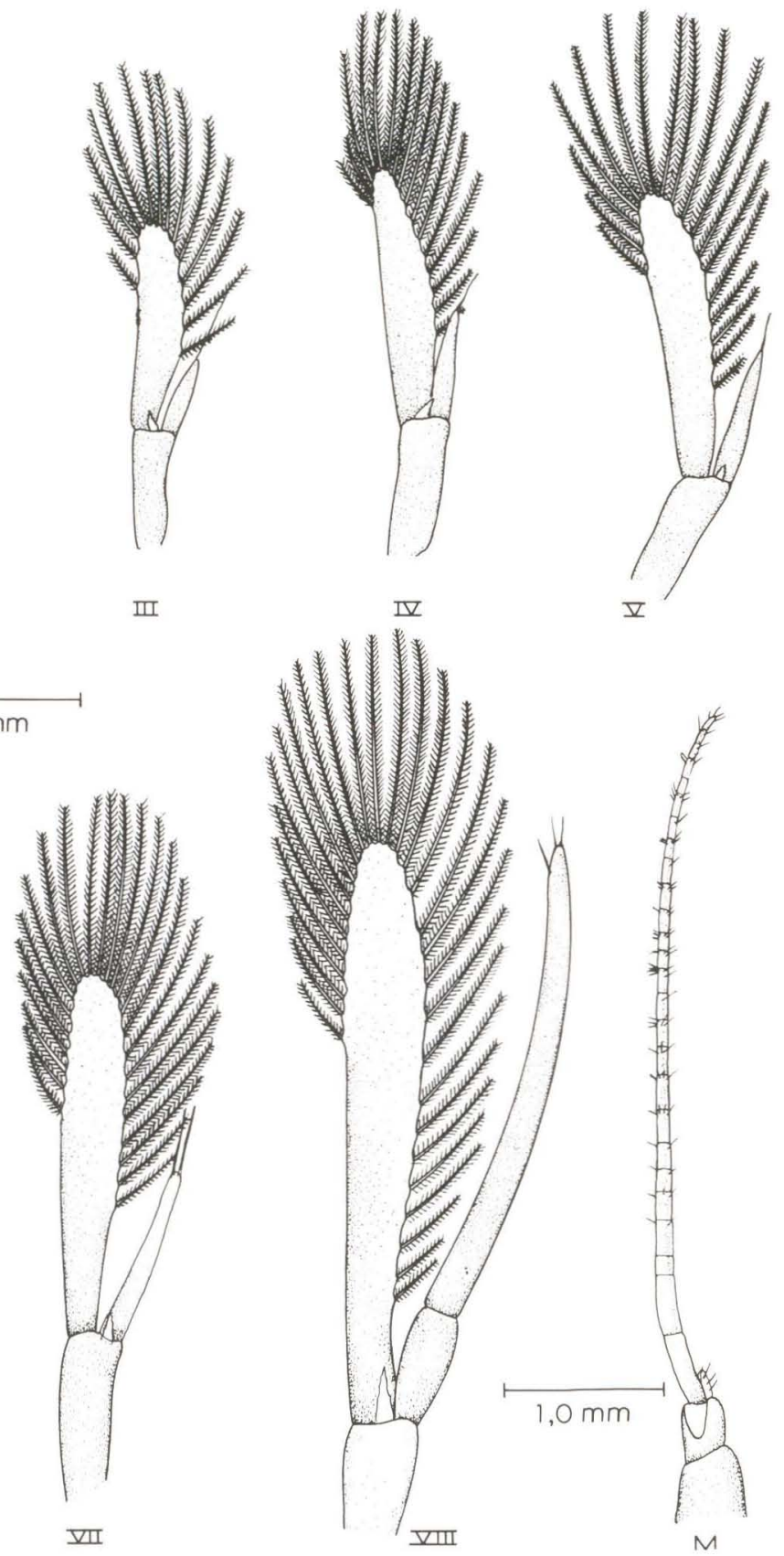

Fig. 4. Dardanus insignis. (I-VIII) Antena dos estágios de zoea; megalopa (M). 


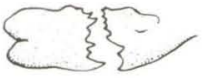

工

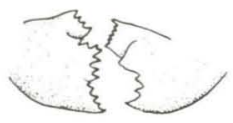

피

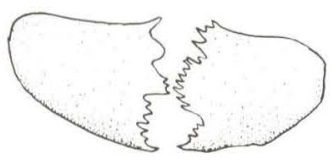

文



VII

$$
\stackrel{\longmapsto}{0,2 \mathrm{~m} \mathrm{~m}}
$$
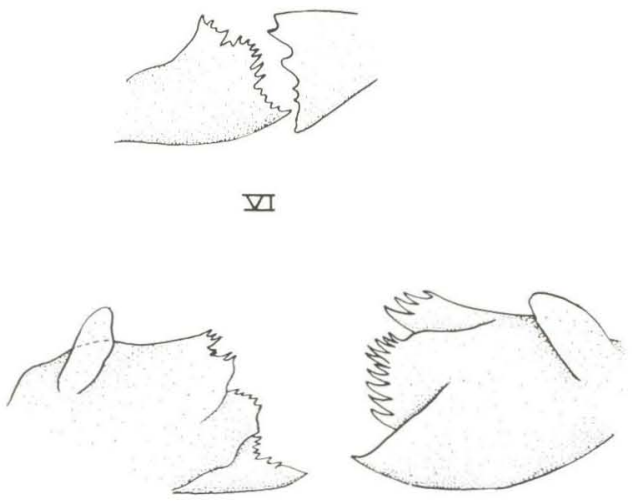

Z

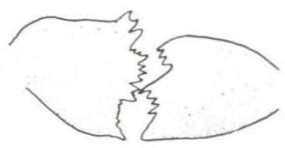

IV

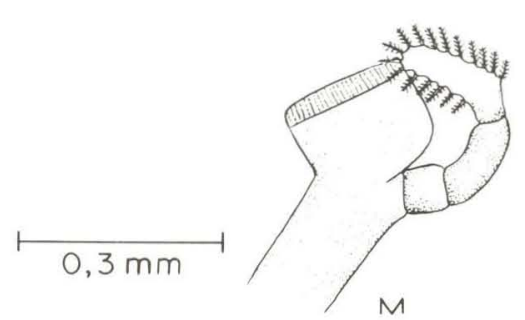

Fig. 5. Dardanus insignis. (I-VIII) Mandíbula dos estágios de zoea; megalopa (M).

para o distal. Exopodito com sete cerdas natatórias.

Terceiro maxilípede (Fig. 10-IV). Bastante semelhante ao da zoea anterior, porém com sete cerdas natatórias no exopodito.

Revta bras. Zool. 12 (3): 471 - 491, 1995 


\section{ZOEA V (Figs 1-V a 10-V)}

Carapaça (Fig. I-V) bastante semelhante a da zoea IV, sem nenhuma modificação relevante. Telso (Fig. 2-V) provido de $10+10$ processos, sendo o primeiro mais anterior e o quarto, modificado em espinhos, quando comparado à zoea anterior. Surge o protopodito dos urópodos, no qual se articulam o exopodito, com 16 (17) cerdas plumosas e endopodito, com oito ou dez cerdas plumosas.

Antênula (Fig. 3-V). Unirreme, 2-segmentada, com quatro estetos e duas cerdas plumosas na porção terminal do exopodito e quatro cerdas plumosas distais e uma subdital no protopodito.

Antena (Fig. 4-V). Exopodito com 18 a 21 cerdas plumosas; endopodito com uma cerda simples. Protopodito com um espinho.

Mandíbula (Fig. 5-V). Semelhante as das zoeas III e IV.

Maxílula (Fig. 6-V). Endopodito não modificado; endito basal com cinco projeções espiniformes e duas pequenas cerdas simples; endito coxal com oito cerdas plumosas.

Maxila (Fig. 7-V). Exopodito com 12 (11) cerdas plumosas marginais; endopodito com as cerdas ligeiramente plumosas; endito basal com quatro cerdas plumosas no lobo distal e cinco no proximal; endito coxal com quatro cerdas plumosas no lobo distal e seis no proximal.

Primeiro maxilípede (Fig. 8-V). Protopodito com oito cerdas simples; endopodito com 4-3-2-2-5 cerdas plumosas, do segmento proximal para o distal; exopodito com sete cerdas natatórias.

Segundo maxilípede (Fig. 9-V). Protopodito com três cerdas simples; endopodito com 2-3-3-5 cerdas plumosas, do segmento proximal para o distal. Exopodito com sete cerdas natatórias.

Terceiro maxilípede (Fig. 10-V). Semelhante ao da zoea anterior.

\section{ZOEA VI (Fig. 1-VI a 10-VI)}

Carapaça (Fig. 1-VI) semelhante a da zoea anterior. Telso (Fig. 2-VI) sub-retangular com $10+10$ processos. Urópodos com protopodito liso; exopodito com 19 (18 a 20) cerdas plumosas e endopodito com 11 (10).

Antênula (Fig. 3-VI). Unirreme, 2-segmentada, com exopodito provido de cinco estetos distais e um subdistal. Protopodito com seis longas cerdas plumosas distais e uma suhdistal.

Antena (Fig. 4-VI). Exopodito com 18 a 22 cerdas plumosas; endopodito com duas cerdas simples; protopodito com um espinho.

Mandíbula (Fig. 5-VI). Semelhante as dos estágios anteriores.

Maxílula (Fig. 6-VI). Endopodito não modificado; endito basal com cinco projeções espiniformes e duas cerdas simples; endito coxal com oito cerdas plumosas.

Maxila (Fig. 7-VI). Exopodito com 11-13 cerdas plumosas; endopodito não modificado; endito basal com quatro cerdas plumosas no lobo distal e cinco no proximal; endito coxal com quatro cerdas plumosas no lobo distal e sete no proximal. 


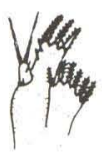

I

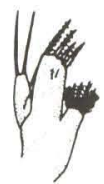

ㅍ

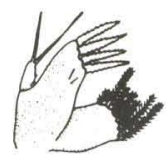

표

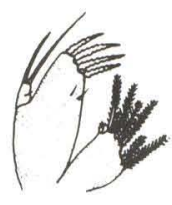

IV

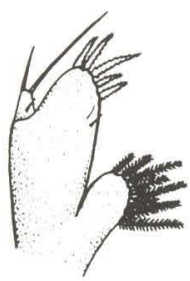

V

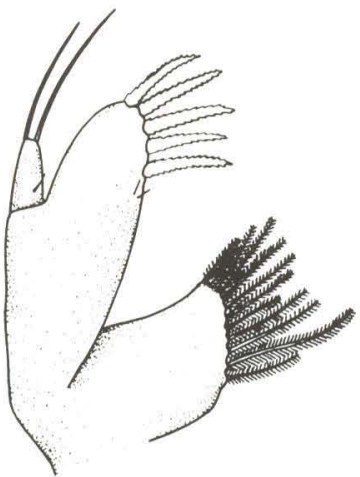

प्रII

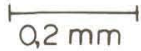

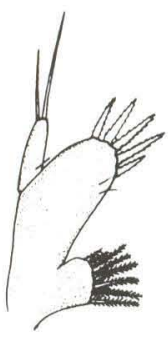

\#I

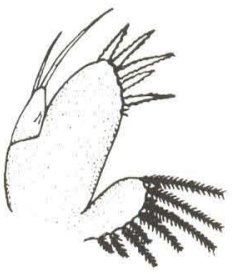

피

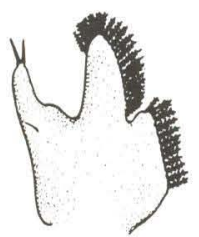

M

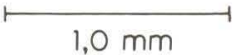

Fig. 6. Dardanus insignis. (I-VIII) Maxilula dos estágios de zoea; megalopa (M).

Primeiro maxilípede (Fig. 8-VI). Protopodito com oito cerdas (cinco plumosas); endopodito com 4-3-2-2-5 cerdas plumosas, do segmento proximal para o distal; exopodito com oito cerdas natatórias.

Segundo maxilípede (Fig. 9-VI). Protopodito com quatro cerdas plumosas; 


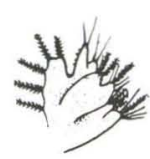

I

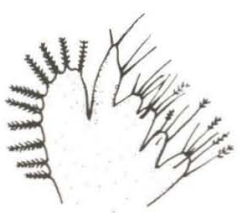

IV

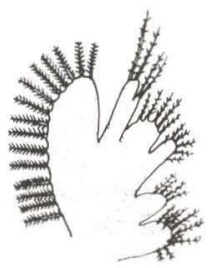

ZII

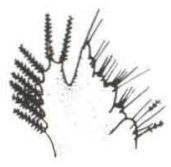

프

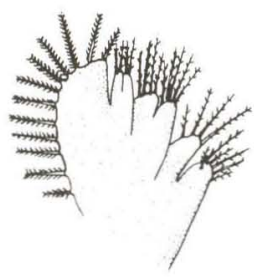

文

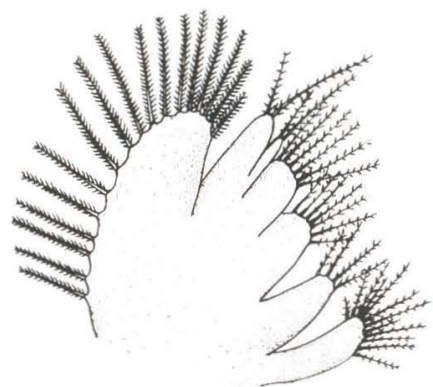

VIII

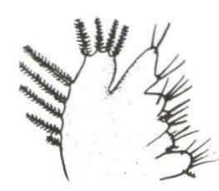

피

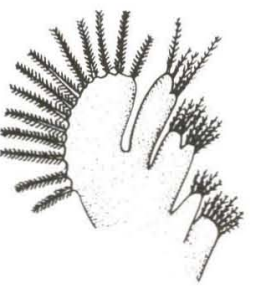

VII

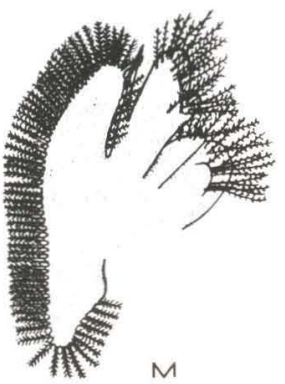

$1,0 \mathrm{~mm}$

Fig. 7. Dardanus insignis. (I-VIII) Maxila dos estágios de zoea; megalopa (M).

endopodito com 2-3-3-5 cerdas plumosas, do segmento proximal para o distal. Exopodito com oito cerdas natatórias.

Terceiro maxilípede (Fig. 10-VI). Exopodito com sete ou oito cerdas natatórias. Demais estruturas semelhantes as das zoeas IV e V.

\section{ZOEA VII (Figs 1-VII a 10-VII)}

Carapaça (Fig. 1-VII) um pouco mais alongada que a de zoea VI. Telso (Fig. 2-VII) retangular, com $10+1+10$ processos. Urópodos com protopodito liso; exopodito com 22 (20-24) cerdas plumosas e endopodito com 14 (11-16). 

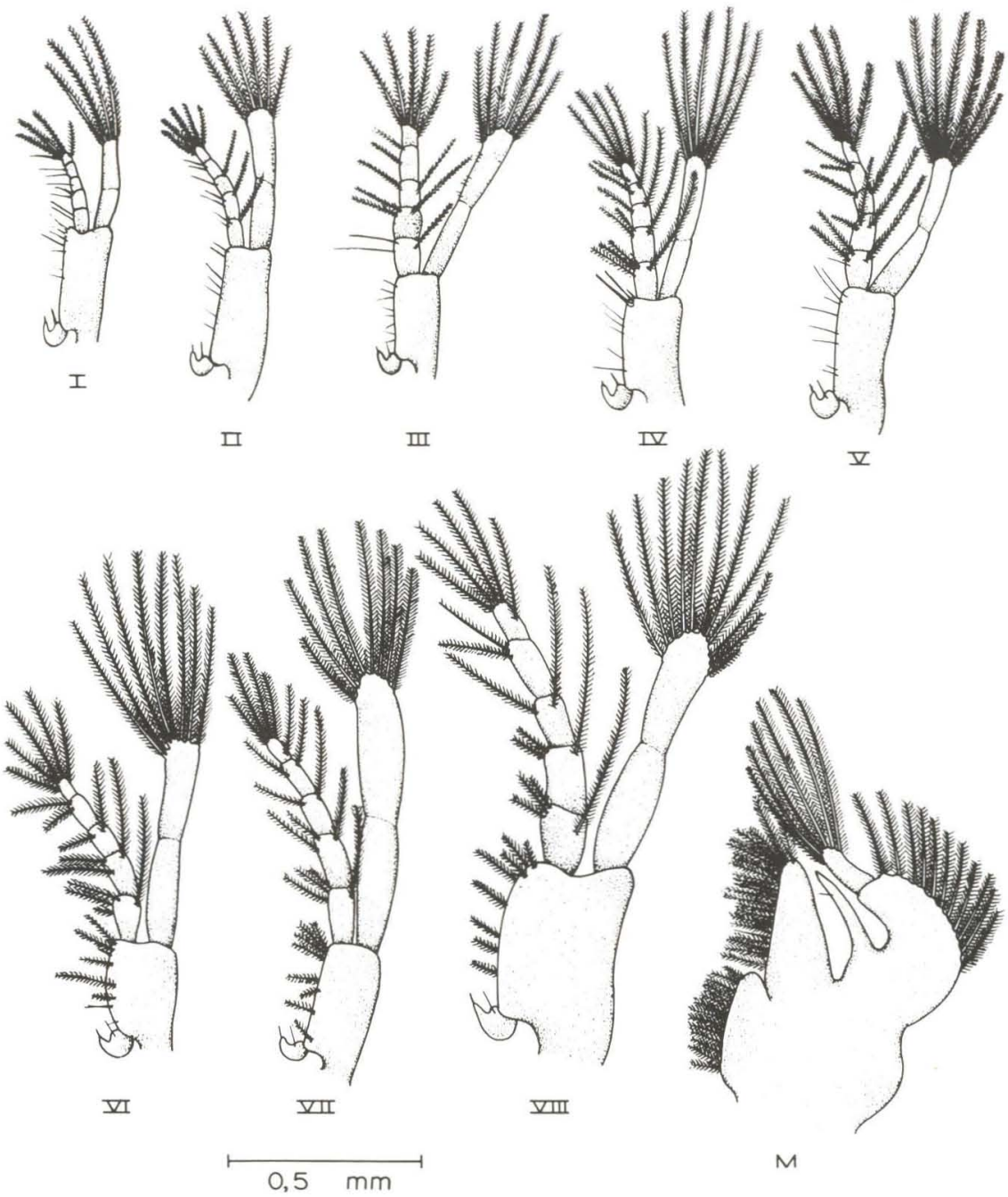

Fig. 8. Dardanus insignis. (I-VIII) Primeiro maxilípede dos estágios de zoea; (M) megalopa.

Antênula (Fig. 3-VII). Birreme, com exopodito provido de três estetos e três cerdas plumosas na porção distal e dois estetos subdistais. Endopodito liso, com aproximadamente um quinto do comprimento do exopodito. Protopodito com cinco longas cerdas plumosas distais e uma subdistal.

Antena (Fig. 4-VII). Exopodito com 22 a 24 cerdas plumosas marginais; endopodito com duas cerdas simples; protopodito com um espinho.

Mandibula (Fig. 5-VII). Semelhante ao estágio anterior.

Maxílula (Fig. 6-VII). Endopodito não modificado; endito basal com cinco projeções espiniformes e duas cerdas simples; endito coxal com oito ou nove cerdas plumosas. 

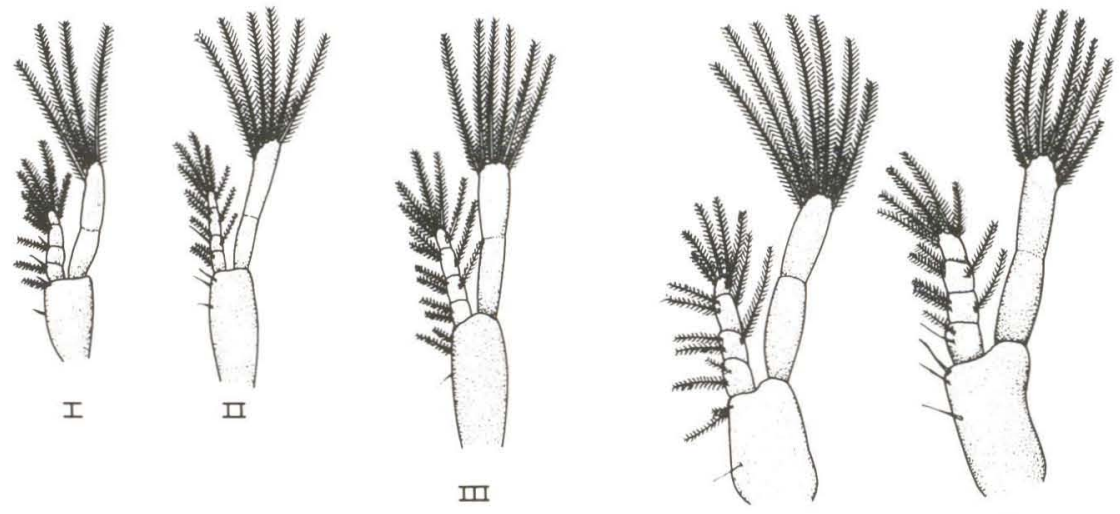

IV

Z

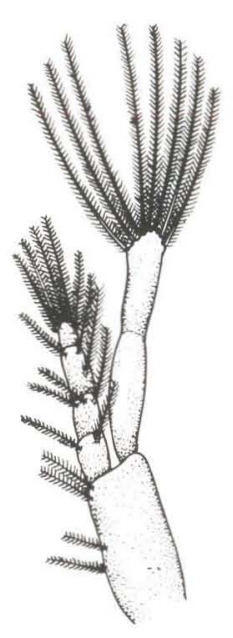

ZI

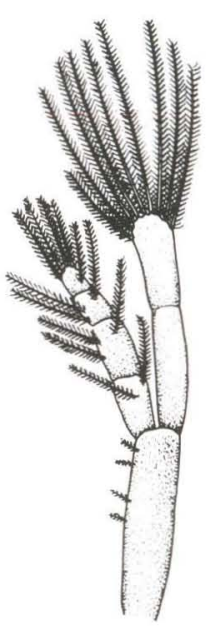

ㅍI

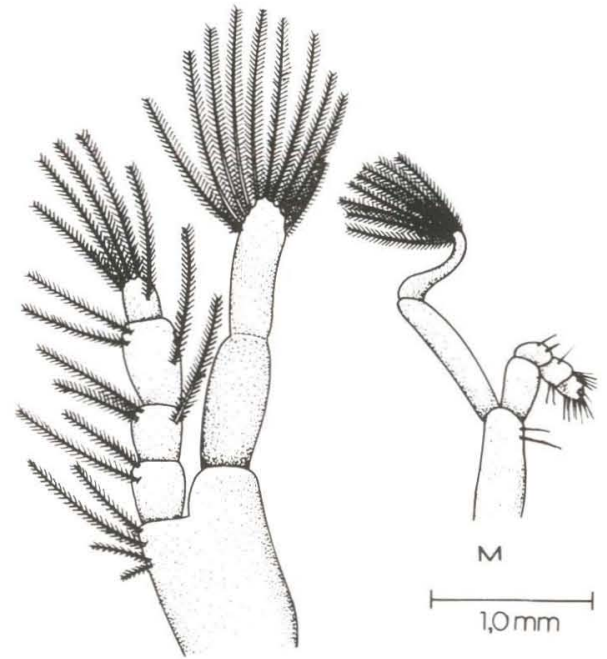

प्पाI

$0,5 \mathrm{~mm}$

Fig. 9. Dardanus insignis. (I-VIII) segundo maxilípede dos estágios de zoea; (M) megalopa.

Maxila (Fig. 7-VII). Exopodito com 15 (13-16) cerdas plumosas; endopodito não modificado; endito basal com cinco cerdas plumosas no lobo distal e seis no proximal; endito coxal com quatro cerdas plumosas no lobo distal e 10 no proximal.

Primeiro maxilípede (Fig. 8-VII). Protopodito com oito cerdas plumosas; endopodito com 4-3-2-2-5 cerdas plumosas, do segmento proximal para o distal. Exopodito com oito cerdas natatórias. 


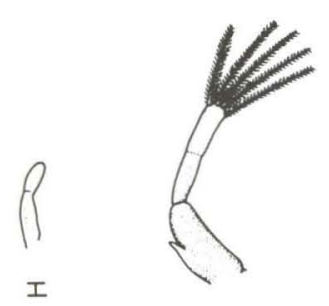

므

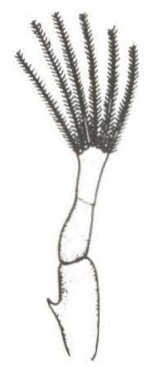

II

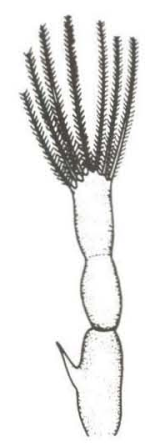

IV

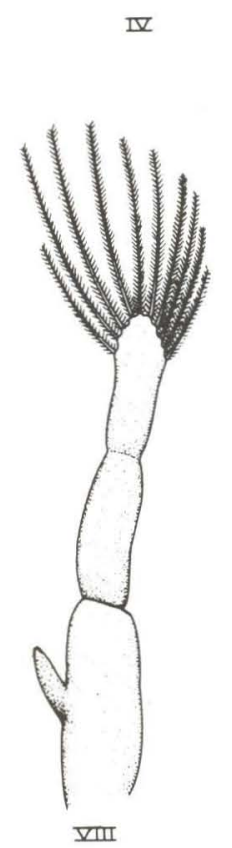

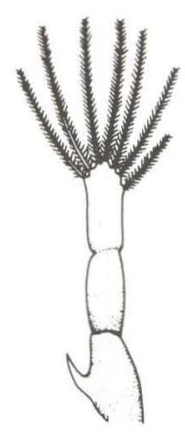

Z


Fig. 10. Dardanus insignis. (I-VIII) terceiro maxilipede dos estágios de zoea; (M) megalopa.

Segundo maxilípede (Fig. 9-VII). Protopodito com quatro cerdas plumosas; endopodito com 2-3-3-5 cerdas plumosas, do segmento proximal para o distal. Exopodito com nove cerdas natatórias.

Terceiro maxilípede (Fig. 10-VII). Exopodito com oito cerdas natatórias. Demais estruturas inalteradas.

\section{ZOEA VIII (Figs 1-VIII a 10 -VIII)}

Carapaça (Fig. 1-VIII) alongada. Somitos abdominais com bulbos de pleópodos $\left(\mathrm{Pl}_{2}-\mathrm{Pl} 5\right)$. Telso (Fig. 2-VIII) retangular com $10+1+10$ processos; urópodos com protopodito liso; exopodito com 29 (30) cerdas plumosas e endopodito com 16 (17) cerdas plumosas. 
Antênula (Fig. 3-VIII). Birreme, com exopodito provido de três cerdas simples e três estetos apicais, além de três grupos de estetos na margem interna, distribuídos em número de três, dois e dois, da região proximal para a distal. Endopodito liso, com aproximadamente um quarto do comprimento do exopodito. Protopodito com cinco longas cerdas plumosas distais e uma subdistal.

Antena (Fig. 4-VIII). Exopodito com 30 (31) cerdas plumosas marginais; endopodito 2-segmentado com comprimento equivalente ao do exopodito e com três cerdas simples; protopodito com um espinho.

Mandíhula (Fig. 5-VIII). Com um pequeno palpo não segmentado.

Maxílula (Fig. 6-VIII). Endopodito não modificado; endito basal com cinco projeções espiniformes e duas cerdas simples; endito coxal com 12 cerdas plumosas

Maxila (Fig. 7-VIII). Exopodito com 17 cerdas plumosas marginais; endopodito não modificado; endito hasal com seis cerdas plumosas no lobo distal e sete no proximal; endito coxal com quatro cerdas plumosas no lobo distal e 12 no lobo proximal.

Primeiro maxilípede (Fig. 8-VIII). Protopodito com oito cerdas plumosas; endopodito com 4-3-2-2-5 cerdas plumosas, do segmento proximal para o distal; exopodito com 11 cerdas natatórias.

Segundo maxilípede (Fig. 9-VIII). Protopodito com quatro cerdas plumosas; endopodito com 2-3-3-5 cerdas plumosas, do segmento proximal para o distal; exopodito com 10 cerdas natatórias.

Terceiro maxilípede (Fig. 10-VIII). Exopodito com 10 cerdas natatórias. Endopodito não ultrapassa o protopodito.

\section{Megalopa (Figs $2 \mathrm{M}$ a $10 \mathrm{M}$ e 11)}

A carapaça e o rostro (Figs llA e l1B) são bastante reduzidos em relação) aos estágios de zoea. O rostro apresenta o ápice arredondado. Os olhos são bem pedunculados. Os segmentos abdominais sofrem um encurtamento ântero-posterior e um alargamento lateral. O telso (Fig.2M) é sub-retangular e sustenta de 12 a 15 cerdas plumosas na sua margem posterior. Urópodos com protopodito liso; endopodito com 24 a 28 cerdas plumosas e nove a 11 grânulos córneos; exopodito com 49 a 53 cerdas plumosas e 14 a 15 grânulos córneos.

Antênula (Fig. 3M). Pedúnculo antenular 3-segmentado provido de alg̨umas cerdas simples esparsas. O exopodito é constituído por 10 segmentos, sendo os sete primeiros curtos e os três últimos alongados. O primeiro segmento é liso: cada um dos seis segmentos subsequentes apresenta entre quatro e seis estetos. Os três últimos segmentos apresentam algumas cerdas simples esparsas. O endopodito é constituído por quatro segmentos alongados providos de algumas cerdas simples

Antena (Fig. 4M). Pedúnculo antenal constituído por cinco segmentos lisos. O exopodito é hastante reduzido, constituído por uma escama; o flagelo antenal é constituído por 21 a 24 segmentos.

Mandíbula (Fig. 5M). Apresenta uma lâmina cortante em lugar dos dentes das zoeas; o palpo é 3-segmentado, sendo que o segmento distal apresenta entre 15 e 17 cerdas plumosas. 

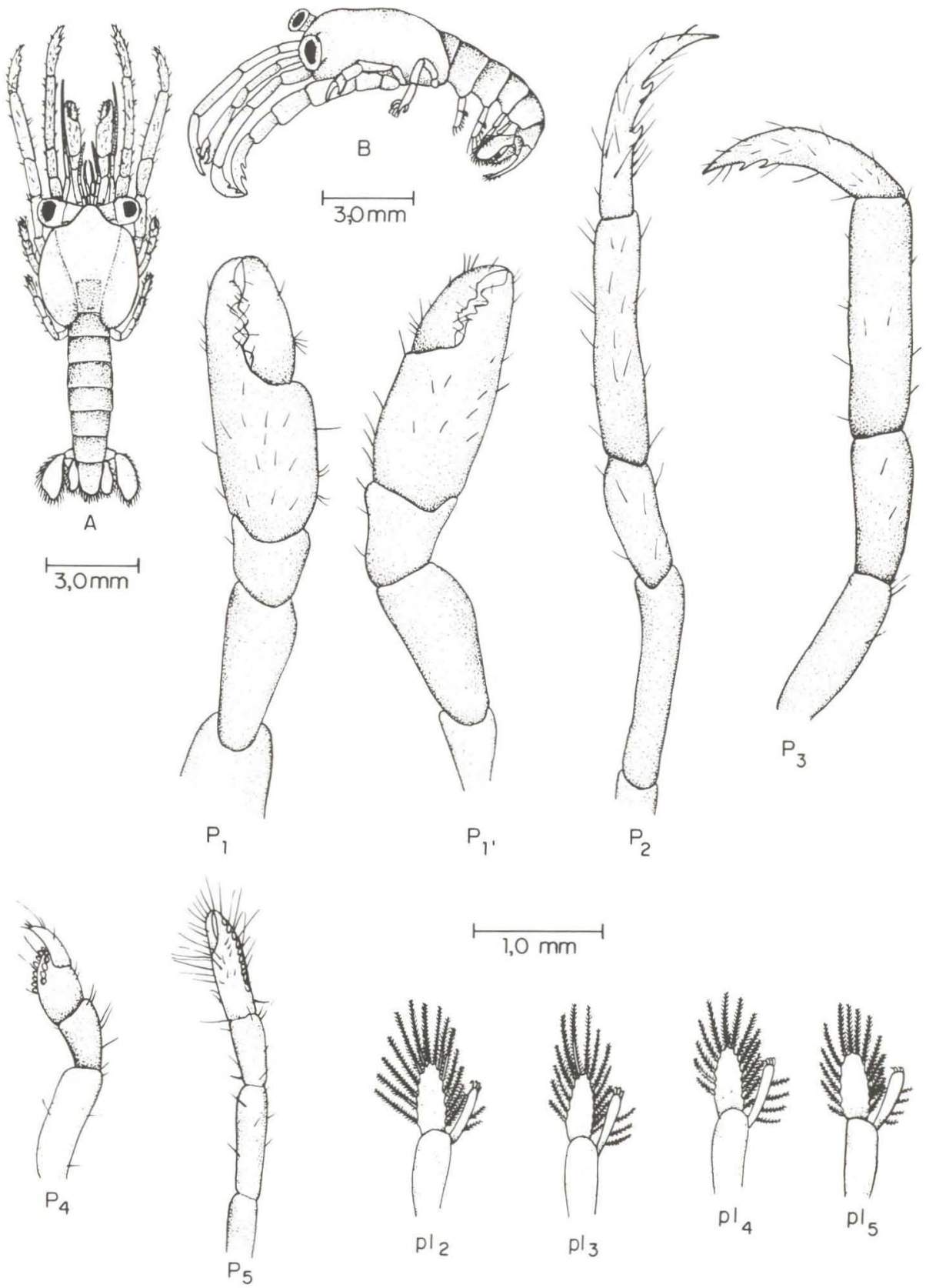

$\longmapsto 1,0 \mathrm{~mm}$
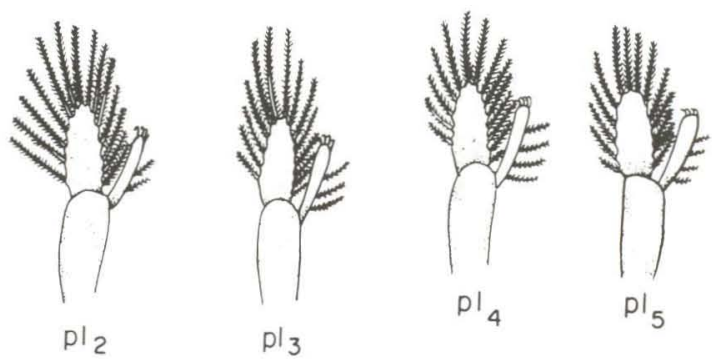

Fig. 11. Dardanus insignis, apêndices da megalopa em vista dorsal $(A)$ e lateral $(B)$. ( $\left.P_{1}-P_{5}\right)$ Pereiópodos, $\left(\mathrm{PI}_{2}-\mathrm{Pl}_{5}\right)$ pleópodos. 
Maxílula (Fig. 6M). Endopodito provido de duas cerdas simples terminais e uma hasal. O endito basal apresenta 20 cerdas plumosas e o endito coxal, 12.

Maxila (Fig. 7M). Exopodito com aproximadamente 71 cerdas plumosas marginais; endopodito provido de duas cerdas simples; endito basal com o lobo distal provido de 14 cerdas plumosas e o proximal com 15; endito coxal com lobo distal provido de 10 cerdas plumosas e o proximal com aproximadamente 25 cerdas.

Primeiro maxilípede (Fig. 8M). O endito coxal apresenta 14 cerdas plumosas marginais; o endito basal apresenta 22 cerdas plumosas; o endopodito apresenta uma única cerda simples mediana; exopodito 2-segmentado com seis cerdas plumosas na porção terminal do segmento distal e 11 cerdas marginais no segmento proximal.

Segundo maxilípede (Fig. 9M). Protopodito alongado, com duas cerdas simples. Exopodito alongado, 2-segmentado, com oito cerdas plumosas na porção terminal; endopodito 4-segmentado com várias cerdas simples, exceto no segmento proximal.

Terceiro maxilípede (Fig. 10M). Protopodito alargado e liso; exopodito 2-segmentado com oito cerdas plumosas terminais; endopodito 5-segmentado com muitas cerdas simples ao longo de todos os segmentos; o segmento proximal apresenta uma crista dentata (seis dentes).

Pereiópodos (Figs $11-\mathrm{P}_{1}$ a $\mathrm{P}_{5}$ ). Os quelípodos são simétricos, providos de pequenas cerdas no própodo e dátilo; este apresenta aproximadamente metade do comprimento do própodo. O mero e o própodo são maiores que os demais segmentos.

O segundo e terceiro pereiópodos apresentam os segmentos recobertos por cerdas e ambos com o dátilo agudo e provido de dois espinhos.

O quarto e o quinto pereiópodos são bem menores que os demais, providos de pequenas cerdas simples; o quarto pereiópodo é suhquelado, apresenta 12 a 17 grânulos córneos marginais no própodo, dispostos em duas fileiras; o quinto é quelado e apresenta 10 a 12 grânulos dispostos em uma única fileira no dorso do própodo.

Pleópodos (Fig. 11- $\mathrm{Pl}_{2}$ a $\mathrm{Pl}_{5}$ ). São em número de quatro pares, inseridos no segundo, terceiro, quarto e quinto somitos abdominais; apresentam, cada um deles, 14 cerdas plumosas no exopodito; o endopodito apresenta quatro cerdas unciformes e 2, 3, 4, 4 cerdas plumosas laterais, respectivamente, do $\mathrm{Pl}_{2}$ para o $\mathrm{Pl} 5$.

As análises morfológicas das megalopas obtidas no conteúdo estomacal de peixes, coletados na natureza, demonstraram que as variações de seus caracteres não excedem os limites constatados para os animais originários dos cultivos em laboratório. A única diferença marcante observada, é que as megalopas da natureza são cerca de $20 \%$ maiores que as obtidas no laboratório. 


\section{DISCUSSÃO E CONCLUSÕES}

Conforme já havia sido deduzido por DECHANCÉ (1961), através de análises de material planctônico, o desenvolvimento larval do gênero Dardanus é constituído por oito estágios de zoea, caracterizando-se como o mais numeroso dentre os Diogenidae conhecidos. KuRATA (1968), em cultivo realizado no laboratório, encontrou sete estágios de zoea no desenvolvimento larval de $D$. arrosor, cujos resultados não foram confirmados no presente trabalho, com a obtenção de oito estágios zoeais em $D$. insignis. Por outro lado, tal como foi constatado por RIEGER \& Hebling (1993) em outros crustáceos com metamorfose longa, as ecdises que ocorreram no final da fase de zoea de $D$. insignis nem sempre conduziram à caracterização de um novo estágio. Este fato explica o aparecimento de até 11 ecdises, em algumas zoeas desta espécie, sem o aparecimento de caracteres que permitissem a identificação de estágios adicionais ao oitavo. Para D. arrosor, segundo KURATA (op. cit.), o número de intermudas é sete ou oito.

Os estudos comparativos dos caracteres das zoeas e megalopas de $D$. insignis com os de $D$. arrosor, a outra espécie do gênero com desenvolvimento larval conhecido, demonstraram, conforme o esperado, uma grande semelhança na morfologia geral. Todavia, os primeiros estágios de zoea de $D$. arrosor apresentam a cutícula da carapaça e dos somitos abdominais constituída por minúsculas escamas, enquanto que, em $D$. insignis, o tegumento é liso. Com relação às megalopas constatou-se que, em $D$. arrosor, o protopodito do urópodo é provido de cinco cerdas, que são ausentes em $D$. insignis. Por outro lado, a megalopa de $D$. venosus, estudada por Provenzano JR. (1963a), que também ocorre no Brasil, apresenta o protopodito do urópodo provido de um forte espinho, que não ocorre em $D$. insignis. Além disso $D$. venosus apresenta 17 cerdas na margem distal do telso, que são em número de $15 \mathrm{em} D$. insignis.

FOREST \& SAINT LAURENT (1967), analisando os ermitões coletados pelo "Calypso" no litoral atlântico da América do Sul, consideraram D. insignis como uma subespécie de D. arrosor, identificando-a como D. arrosor insignis. O presente estudo, aliado a uma ampla análise das larvas de outras espécies de Dardanus até então conhecidas, com suas respectivas distribuições geográficas, permite concluir que $D$. insignis e $D$. arrosor são espécies absolutamente distintas. concordando com Williams $(1965,1984)$, que não inclui esta última no Atlântico Ocidental.

AGRADECIMENTOS. Ao Sr. Jaime Roberto Somera, desenhista do Departamento de Zoologia da Universidade Estadual Paulista, pela arte final nas figuras.

\section{REFERÊNCIAS BIBLIOGRÁFICAS}

Boraschi, L. 1921. Osservazione sulle larve dei crostacei decapodi: brachiuri e anomuri. Mem R. Com. talassogr. ital. 87: 1-32.

Bourdillon-Casanova, L. 1960. Le méroplancton du Golfe de Marseille: les larves du Crustacés Décapodes. Rec. Trav. Sta. mar. Endoume 30: 1-286. 
Brossi-Garcia, A.L. \& N.J. Hebling. 1983. Desenvolvimento pós-embrionário de Clihanarius antillensis Stimpson, 1859 (Crustacea, Diogenidae), em laboratório. Bolm Zool. Univ. São Paulo 6: 89-111.

DeChancÉ, M. 1961. Nombre et caractères des stades larvaires dans le genre Dardanus (Crustacé, Décapode, Paguride). C.R. Acad. Sci. 253: 529-531.

1962. Remarques sur les premiers stades larvaires de plusieurs espèces Indopacifiques du genre Dardanus (Crustacès, Decapodes, Pagurides). Bull. Mus. Nat. Hist. Nat. 34 (1): 82-94.

Forest, J. \& M. Saint Laurent. 1967. Campagne de La Calypso au large Des Côtes Atlantiques de La Amerique du Sud (1961/62). II. Ann. Inst. Océan. 45 (2): $1-171$.

Hebling, N.J. \& A. Fransozo. 1982. Desenvolvimento pós-embrionário de Paguristes erythops Holtuis, 1959 (Decapoda, Diogenidae) em laboratório. Rev. Brasil. Biol. 42 (1): 117-128.

ISSEL, R. 1910. Ricerche intorno alla biologia ed alla morfologia dei crostacei decapodi. Parte I: Studi sui paguridi. Arch. Zool., Napoli, 4: 335-397.

Kurata, H. 1968. Larvae of Decapoda Anomura of Arasaki, Sagami Bay - Il. Dardanus arrosor (Herbst) (Diogenidae). Bull. Tokai Reg. Fish. Res. Lah. 56: $173-180$.

NAYAK, V.N. \& V.S. KaKATI. 1977. Occurrence of the hermit crah Durdanus setifer (H. Milne Edwards) (Decapoda, Anomura) at Kawar with a description of the first zoeal stage. J. Bombay nat. Hist. Soc. 75 (2): 286-291.

Negreiros-Fransozo, M.L. \& N.J. Hebling. 1983. Desenvolvimento pósembrionário de lsocheles sawayai Forest e Saint Laurent, 1967 (Decapoda, Diogenidae), em laboratório. Papéis Avulsos Dept. Zool., São Paulo, 35 (4): 41-53.

Pike, R.B. \& D.I. Williamson. 1960. Larvae of Decapod Crustacea of the Families Diogenidae and Paguridae from the Bay of Naples. Pubbl. Staz. Zool. Napoli 31 (3): 494-521.

Provenzano JR., A.J. 1963a. The glaucothoe stage of Dardamus venosus (H. Milne-Edwards) (Decapoda: Anomura). Bull, Mar. Sci. Gulf Caribhean 13 (1): 11-22.

1963b. The glaucothoes of Petrochirus diogenes (L.) and two species of Dardanus (Decapoda: Diogenidae). Bull. Mar. Sci. Gulf Caribhean 13 (2): 242-261.

Rieger, P.J. \& N.J. Hebling. 1993. Desenvolvimento larval de Hepatus pudibundus (Herbst, 1785) (Decapoda, Calappidae), em laboratório. Rev. Brasil. Biol. 53 (4): 513-528.

Williams, A.B. 1965. Marine decapod crustaceans os the Carolinas. Fishery Bull., Washington, 65 (1): 1-298. 1984. Shrimps, lobsters and crabs os the Atlantic coast os the eastern United States, Maine to Florida. Washington, Smithsonian Institution Press, XVIII +500p. 